\title{
Desempenho vitícola de variedades autóctones italianas em condição de elevada altitude no Sul do Brasil
}

\author{
Alberto Fontanella Brighenti( ${ }^{(1)}$, Aparecido Lima da Silva $^{(1)}$, Emilio Brighenti( ${ }^{(2)}$, Duilio Porro( ${ }^{(3)}$ e Marco Stefanini ${ }^{(3)}$ \\ (1)Universidade Federal de Santa Catarina, Centro de Ciências Agrárias, Departamento de Fitotecnia, Rodovia Admar Gonzaga, no 1.346, \\ Itacorubi, CEP 88040-900 Florianópolis, SC, Brasil. E-mail: brighenti_07@hotmail.com, alsilva@cca.ufsc.br (2)Empresa de Pesquisa \\ Agropecuária e Extensão Rural de Santa Catarina, Estação Experimental de São Joaquim, Rua José Araújo Lima, no 102, Jardim Caiçara, \\ CEP 88600-000 São Joaquim, SC, Brasil. E-mail: brighent@epagri.sc.gov.br (3)Istituto Agrario di San Michele all'Adige, Fondazione Edmund \\ Mach, Via E. Mach, 138010, San Michele all’Adige, TN, Itália. E-mail: duilio.porro@fmach.it, marco.stefanini@fmach.it
}

Resumo - O objetivo deste trabalho foi avaliar o desempenho vitícola de 12 variedades autóctones italianas cultivadas a $1.400 \mathrm{~m}$ de altitude, em São Joaquim, SC. As seguintes variedades foram avaliadas em três ciclos: Prosecco, Verdicchio e Vermentino (brancas); e Aglianico, Aleatico, Ancellotta, Lambrusco Grasparossa, Montepulciano, Negroamaro, Rebo, Sagrantino e Sangiovese (tintas). Utilizou-se o delineamento experimental inteiramente casualizado, com cinco repetições de oito plantas para cada variedade. Os estádios fenológicos analisados foram: brotação, floração, mudança de cor das bagas e maturidade. No momento da colheita, avaliaram-se: produtividade e produção por planta, teor de sólidos solúveis totais ( $\left.{ }^{\circ} \mathrm{Brix}\right)$, acidez total titulável $\left(\right.$ meq $\left.\mathrm{L}^{-1}\right), \mathrm{pH}$, e teores de antocianinas e de polifenóis totais. A amplitude térmica em torno de $10^{\circ} \mathrm{C}$, durante a maturação, influenciou positivamente a qualidade da uva. As variedades brancas mais bem adaptadas às condições de São Joaquim foram a Vermentino e a Verdicchio, com produtividades acima de 3,9 $\mathrm{Mg} \mathrm{ha}^{-1}$, sólidos solúveis acima de $18^{\circ}$ Brix e teores de polifenóis totais acima de $500 \mathrm{mg} \mathrm{L}^{-1}$. As variedades tintas mais bem adaptadas foram a Sangiovese, a Sagrantino e a Montepulciano, com produtividades em torno de $6 \mathrm{Mg} \mathrm{ha}^{-1}$, sólidos solúveis entre 19 e $21,5^{\circ}$ Brix e teores de polifenóis totais acima de $780 \mathrm{mg} \mathrm{L}^{-1}$. As baixas temperaturas durante a brotação e o volume de precipitação pluvial são os aspectos climáticos mais limitantes ao cultivo das variedades avaliadas, em São Joaquim.

Termos para indexação: Vitis vinifera, desempenho agronômico, fenologia, maturação fenólica, maturação tecnológica, "terroir".

\section{Viticultural performance of native Italian varieties in high-altitude conditions in Southern Brazil}

\begin{abstract}
The objective of this work was to evaluate the viticultural performance of 12 native Italian varieties, cultivated at 1,400 m of altitude in São Joaquim, state of Santa Catarina, Brazil. The following varieties were evaluated during three cycles: Prosecco, Verdicchio, and Vermentino (white); and Aglianico, Aleatico, Ancellotta, Lambrusco Grasparossa, Montepulciano, Negroamaro, Rebo, Sagrantino, and Sangiovese (red). A completely randomized design was used, with five replicates of eight plants for each variety. The phenological stages evaluated were: budbreak, full bloom, veraison, and maturity. At harvest, the following were evaluated: yield and productivity per plant, total soluble solids ( $\left.{ }^{\circ} \mathrm{Brix}\right)$, titratable total acidity $\left(\mathrm{meq} \mathrm{L}^{-1}\right)$, $\mathrm{pH}$, and contents of anthocyanin and total polyphenol. Thermal amplitude around $10^{\circ} \mathrm{C}$ during maturation positively influenced grape quality. The white varieties better adapted to the conditions of São Joaquim were Vermentino and Verdicchio, with yields above $3.9 \mathrm{Mg} \mathrm{ha}^{-1}$, soluble solids above $18^{\circ} \mathrm{Brix}$, and total polyphenol contents above $500 \mathrm{mg} \mathrm{L}^{-1}$. The red varieties better adapted were Sangiovese, Sagrantino, and Montepulciano, with yields around $6 \mathrm{Mg} \mathrm{ha}^{-1}$, soluble solids between 19 and $21.5^{\circ}$ Brix, and total polyphenol contents above $780 \mathrm{mg} \mathrm{L}^{-1}$. Low temperatures during budbreak and the volume of rainfall are the most limiting climatic aspects for cultivating the evaluated varieties in São Joaquim.
\end{abstract}

Index terms: Vitis vinifera, agronomic performance, phenology, phenolic maturation, technological maturation, terroir.

\section{Introdução}

A vitivinicultura em regiões de altitude elevada, no Estado de Santa Catarina, tem se destacado nos últimos anos, graças à qualidade das uvas e dos vinhos produzidos (Burin et al., 2011; Gris et al., 2011; Malinovski et al., 2012). No entanto, o cultivo da 
videira nesses locais é recente, com cerca de dez anos, o que torna relevante a identificação de variedades adaptadas às condições dessas regiões, capazes de produzir uvas e vinhos de alta qualidade (Brighenti et al., 2013).

Fatores genéticos são determinantes para a composição da uva e devem ser estudados juntamente com aspectos ambientais, que incluem a adaptação ao ambiente; tecnológicos, referentes às técnicas de manejo; e fisiológicos, pertinentes sobretudo ao processo de maturação (Schneider, 2006). Fatores ambientais, como solo e clima, aliados a características varietais e de cultivo definem o "terroir" de uma região, que tem influencia marcante sobre a qualidade das uvas e do vinho. O clima é especialmente importante para a definição das potencialidades das regiões de cultivo, pois o desempenho da videira é muito afetado pelos elementos meteorológicos (Deloire et al., 2005). A qualidade da uva e do vinho, por exemplo, depende da temperatura durante a maturação, e a variedade mais indicada para uma determinada região será aquela cujo desenvolvimento coincide com a duração da estação de crescimento (Jackson \& Lombard, 1993).

O conhecimento dos estádios fenológicos é uma exigência da viticultura, uma vez que possibilita a racionalização e a otimização de práticas culturais. A classificação baseada na época de brotação é importante para os viticultores, pois permite o uso de variedades de brotação precoce em locais com baixo risco de ocorrência de geadas tardias (Mandelli et al., 2003).

Em novas regiões vitícolas, as variedades inicialmente plantadas e avaliadas, com poucas exceções, correspondem àquelas de renome internacional, originárias da França e, em menor escala, da Itália e de Portugal. Nos vinhedos de altitude elevada de Santa Catarina, as principais variedades plantadas são a Cabernet Sauvignon, com a maior área, seguida pela Merlot e pela Chardonnay. As principais variedades cultivadas e práticas de elaboração estão amplamente difundidas em todas as regiões produtoras de vinhos. Isso enfatiza o aspecto global da produção de vinhos, e minimiza a contribuição das variedades, e do meio onde elas são produzidas, sobre o padrão dos vinhos. Nesse contexto, viticultores em todo o mundo estão reavaliando o valor enológico e o potencial de marketing do patrimônio varietal local (Mannini, 2004).
Para oferecer novas opções de variedades aos viticultores, foi iniciado, em 2006, o projeto Tecnologias para o Desenvolvimento da Vitivinicultura Catarinense, cuja finalidade é introduzir e avaliar a adaptação de diversas variedades italianas nas principais regiões de altitude do Estado, com a possibilidade de produção de uvas para vinho com elevada qualidade e tipicidade, que expresse as características dessa nova região produtora. Portanto, é necessário que se conheça bem o ambiente de cultivo e as variedades a serem cultivadas, e que se desenvolvam práticas culturais e enológicas que aumentem o potencial das variedades escolhidas, de modo a obter vinhos que sejam, em última análise, a expressão de um território.

O objetivo deste trabalho foi avaliar o desempenho vitícola de 12 variedades autóctones italianas cultivadas a 1.400 m de altitude, em São Joaquim, Santa Catarina.

\section{Material e Métodos}

A pesquisa foi realizada na Estação Experimental da Empresa de Pesquisa Agropecuária e Extensão Rural de Santa Catarina, localizada no Município de São Joaquim (2816'30"S, 4956'09"W, a 1.400 m de altitude). $\mathrm{O}$ vinhedo (Vitis vinifera $\mathrm{L}$.) foi implantado em 2006, com espaçamento de 3,00 m entre linhas e $1,50 \mathrm{~m}$ entre plantas, e sistema de condução tipo espaldeira. Os solos da região se enquadram nas classes Cambissolo Húmico, Neossolo Litólico e Nitossolo Háplico, desenvolvidos a partir de rocha riodacito e basalto (Solos do Estado de Santa Catarina, 2004). Foram avaliados os ciclos 2010/2011, 2011/2012 e 2012/2013. O clima da região, segundo a classificação de Koeppen, é do tipo $\mathrm{Cfb}$, mesotérmico, úmido, sem estação seca, com verão fresco $\left(<22^{\circ} \mathrm{C}\right)$ (Benez et al., 2002).

As variedades estudadas foram: Prosecco, Verdicchio e Vermentino (brancas); e Aglianico, Aleatico, Ancellotta, Lambrusco Grasparossa, Montepulciano, Negroamaro, Rebo, Sagrantino e Sangiovese (tintas). Utilizou-se o delineamento experimental inteiramente casualizado, com cinco repetições de oito plantas de cada variedade de videira, o que totalizou 480 plantas.

O monitoramento das condições meteorológicas foi realizado com uso dos dados da Estação Meteorológica Automática localizada na Estação Experimental de São Joaquim. Foram registradas as variáveis meteorológicas: temperaturas do ar média, máxima e 
mínima $\left({ }^{\circ} \mathrm{C}\right)$; precipitação pluvial $(\mathrm{mm})$; e amplitude térmica $\left({ }^{\circ} \mathrm{C}\right)$.

Para verificar a aptidão vitícola da região, foram calculados a temperatura média ao longo da estação de crescimento (Hall \& Jones, 2010) e o período livre de geadas (Jackson, 2008). O primeiro índice consiste na temperatura média do ar entre setembro (brotação) e abril (maturidade), e o segundo, no número médio de dias entre a última geada de inverno ou a primavera e a primeira geada do outono, de acordo com a série histórica.

A determinação da fenologia das plantas foi feita por um único avaliador, por meio de observações visuais realizadas semanalmente após a poda, em cinco plantas previamente selecionadas, nos três ciclos estudados. Foram determinados o início da brotação, a plena floração, a mudança de cor das bagas e a maturidade, conforme classificação proposta por Baillod \& Baggiolini (1993). Como critério utilizado para avaliar a adaptação de variedades em novas regiões de cultivo, foi determinada a duração do subperíodo entre a mudança de cor das bagas até a maturidade das uvas (Fregoni, 2006).

As datas de ocorrência dos principais estádios fenológicos das variedades avaliadas foram comparadas às das variedades mais cultivadas na região, tendo-se utilizado os dados obtidos por Brighenti et al. (2013), em que Chardonnay é precoce; Merlot, intermediária; e Cabernet Sauvignon, tardia.

O ponto de colheita foi determinado de acordo com a sanidade dos cachos, baseado na incidência de podridão, ou com os teores de sólidos solúveis totais, em torno de $20^{\circ}$ Brix. A produtividade das plantas foi avaliada na colheita, por meio da pesagem dos cachos (kg por planta) de 25 plantas previamente selecionadas (cinco plantas situadas na parte central de cada repetição). A produção por planta (kg por planta) foi calculada por meio dos valores de massa fresca dos cachos e do número de cachos por planta. A produtividade estimada $\left(\mathrm{Mg} \mathrm{ha}^{-1}\right)$ foi obtida a partir da densidade de plantas por hectare e da produção por planta. O índice de fertilidade foi determinado por meio da divisão do número de cachos por planta pelo número de ramos por planta.

As análises de maturação foram realizadas no momento da colheita. Do mosto obtido pelo esmagamento das bagas das uvas, foram determinados os sólidos solúveis totais ( ${ }^{\circ}$ Brix), a acidez total titulável (meq $\mathrm{L}^{-1}$ ) e o $\mathrm{pH}$ de cada variedade, segundo o método recomendado pelo Office International de la Vigne et du Vin (Recueil des méthodes internationales d'analyse des vins et des moûts, 2009).

A quantificação das antocianinas foi realizada por meio do $\mathrm{pH}$ diferencial, auferido com espectrofotômetro, de acordo com Giusti \& Wrolstad (2001). O conteúdo de polifenóis totais foi determinado conforme Singleton \& Rossi (1965), com o método de Folin-Ciocalteu, com leituras no espectrofotômetro.

Para a análise dos resultados, utilizaram-se as estatísticas descritivas: média, desvio-padrão e coeficiente de variação. Realizaram-se análises de componentes principais para os resultados de produtividade $\left(\mathrm{Mg} \mathrm{ha}^{-1}\right)$, número de cachos por planta, sólidos solúveis totais, acidez total titulável, $\mathrm{pH}$, antocianinas e polifenóis totais. As análises foram realizadas com o programa Fitopac 2 (Shepherd, 2010).

\section{Resultados e Discussão}

Em setembro, no ciclo 2012/2013, observou-se queda nas temperaturas médias, com ocorrência de geada tardia, que causou danos às variedades de brotação precoce e médio-precoce, com morte da parte aérea recém-brotada nas variedades Prosecco, Aleatico, Rebo, Lambrusco Grasparossa, Verdicchio e Sangiovese (Figura 1). O período livre de geadas, em São Joaquim, é de aproximadamente 180 dias. O número mínimo de dias livres de geada necessários para a viticultura produtiva é de 180 (Jackson, 2008). As variedades com brotação em agosto estão especialmente expostas ao risco de danos por geadas, comum nas regiões de elevada altitude durante esse período (Brighenti et al., 2013).

A temperatura média ao longo da estação de crescimento foi de $15^{\circ} \mathrm{C}$. Em geral, quando a temperatura média ao longo da estação de crescimento se encontra entre 13 e $21^{\circ} \mathrm{C}$, é possível considerar a região apta à produção de uvas viníferas de qualidade (Hall \& Jones, 2010).

As amplitudes térmicas registradas durante os ciclos analisados (Figura 1) foram semelhantes às descritas por Gris et al. (2011) e Malinovski et al. (2012), que relataram amplitude térmica próxima a $10^{\circ} \mathrm{C}$, para a localidade de São Joaquim, considerada ideal para produção de uvas de qualidade (Jackson, 
2008). Os valores obtidos no presente trabalho são inferiores aos relatados em Santiago, Chile $\left(15,8^{\circ} \mathrm{C}\right)$, e próximos aos da Região de Bordeaux $\left(10,5^{\circ} \mathrm{C}\right)$, durante a maturação (Tonietto \& Carbonneau, 2004). Temperaturas elevadas resultam, quase que invariavelmente, em maiores teores de sólidos solúveis totais. Noites frias associadas a temperaturas diurnas quentes são capazes de reduzir o $\mathrm{pH}$ e aumentar os níveis de acidez, em comparação a dias e noites quentes (Jackson \& Lombard, 1993).

Para os ciclos 2010/2011, 2011/2012 e 2012/2013, o volume total de precipitação registrado foi de $1.821,1.518$ e $1.195 \mathrm{~mm}$, respectivamente (Figura 2). $\mathrm{O}$ período fenológico com o maior percentual de dias com chuva, em todos os ciclos avaliados, foi a maturação (Tabela 1), resultados semelhantes foram obtidos por Luciano et al. (2013) nos ciclos 2008/2009 e 2009/2010 em São Joaquim. O ciclo 2010/2011 foi especialmente chuvoso, com precipitações acima da média em janeiro, fevereiro e março. No ciclo
2012/2013, após um período de seca em janeiro, foi registrada precipitação acima da média em fevereiro, o que comprometeu a qualidade da uva, em razão da ocorrência de doenças.

A frequência e a distribuição de chuvas são elementos climáticos de grande importância, pois a água livre sobre as folhas e os frutos é o principal fator para desencadear o início de infecções fúngicas na videira (Chavarria et al., 2007). As variedades mais afetadas pelo excesso de chuvas foram: Verdicchio, Aglianico, Sangiovese, Negroamaro e Sagrantino, que apresentam maior compactação dos cachos (Calò et al., 2006). Sabe-se que botritis e podridão ácida influem de maneira decisiva na produtividade do vinhedo, e que variedades de cachos compactos são mais suscetíveis a essas doenças (Margoni \& Mattedi, 2004).

A grande variação nas datas de ocorrência dos estádios fenológicos (Tabela 1) foi decorrente da alta diversidade genética do germoplasma italiano de $V$. vinifera, resultante da seleção humana e natural que
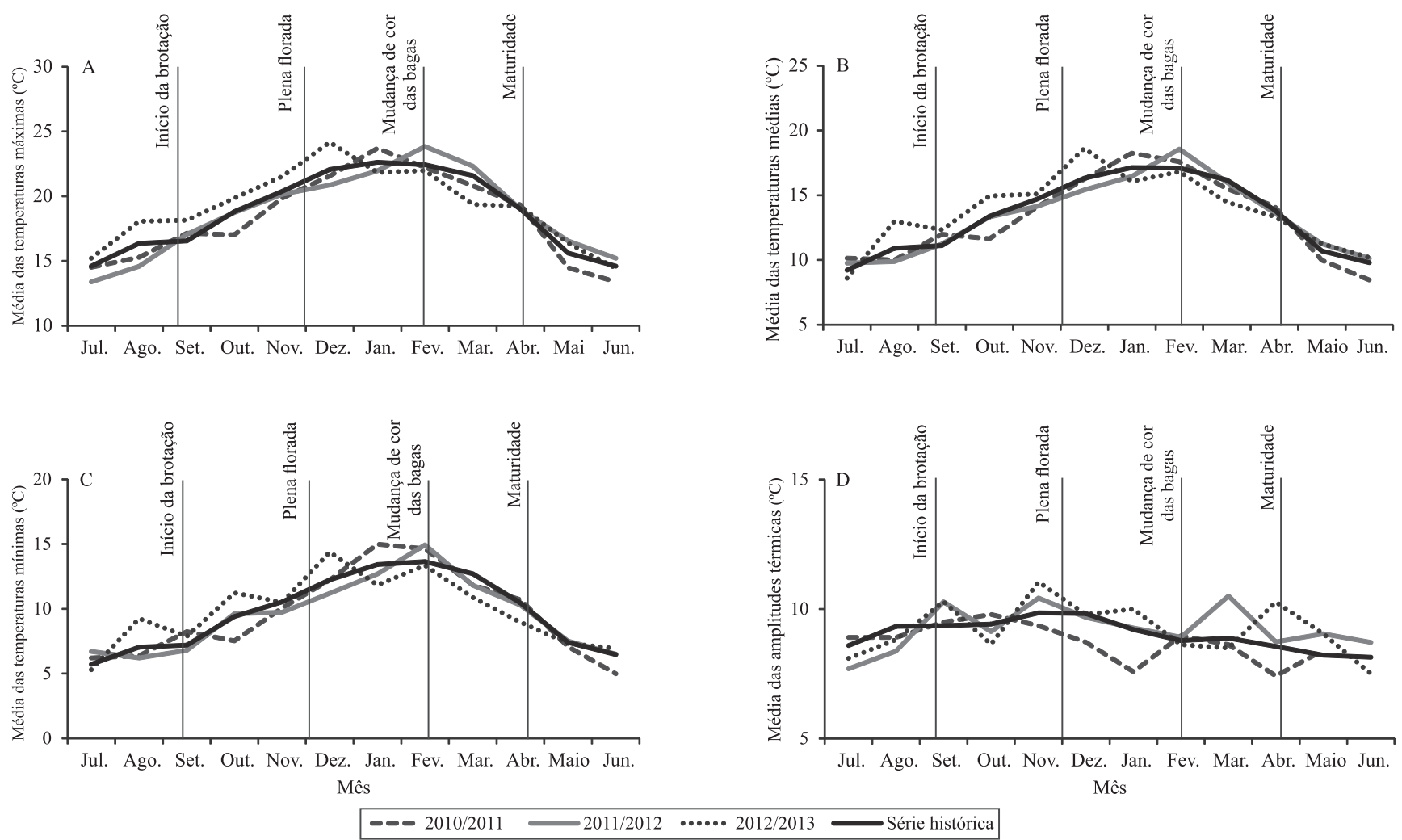

Figura 1. Médias mensais das temperaturas máxima (A), média (B), mínima (C) e da amplitude térmica (D) da série histórica (SH) de 1983 a 2013 e dos ciclos 2010/2011, 2011/2012 e 2012/2013, durante o ciclo vegetativo e reprodutivo da videira (Vitis vinifera), em São Joaquim, SC. 
estabeleceu estreitas relações entre as variedades e o ambiente (Andreini et al., 2009).

De acordo com as datas de brotação, constatou-se que as variedades Prosecco e Lambrusco Grasparossa exibiram brotação precoce, semelhante à Chardonnay; Aleatico e Verdicchio foram mais precoces que a Merlot; Sangiovese e Rebo tiveram brotação intermediária, semelhante à Merlot; Vermentino, Aglianico, Ancellotta, Negroamaro e Sagrantino apresentaram brotação mais tardia que a Merlot; e Montepulciano foi tardia, semelhante à Cabernet Sauvignon.

Entre a variedade mais precoce e a tardia, houve diferença média de 40 dias na data de brotação. Mandelli et al. (2003) obtiveram resultado similar ao estudar a fenologia de diferentes variedades na Serra Gaúcha.

A data média de ocorrência da plena florada das variedades avaliadas ocorreu entre a segunda quinzena de novembro e a primeira quinzena de dezembro (Tabela 1). Prosecco, Aleatico e Rebo apresentaram floração semelhante à Chardonnay; Aglianico, Negroamaro, Sagrantino e Montepulciano, à Cabernet Sauvignon; e as demais variedades apresentaram plena florada semelhante à Merlot. A floração das variedades mais precoces ocorreu, em média, 22 dias antes da floração das mais tardias.

A maturação das variedades aconteceu ao longo de abril e se estendeu até o início de maio (Tabela 1). As variedades Verdicchio e Rebo apresentaram data de

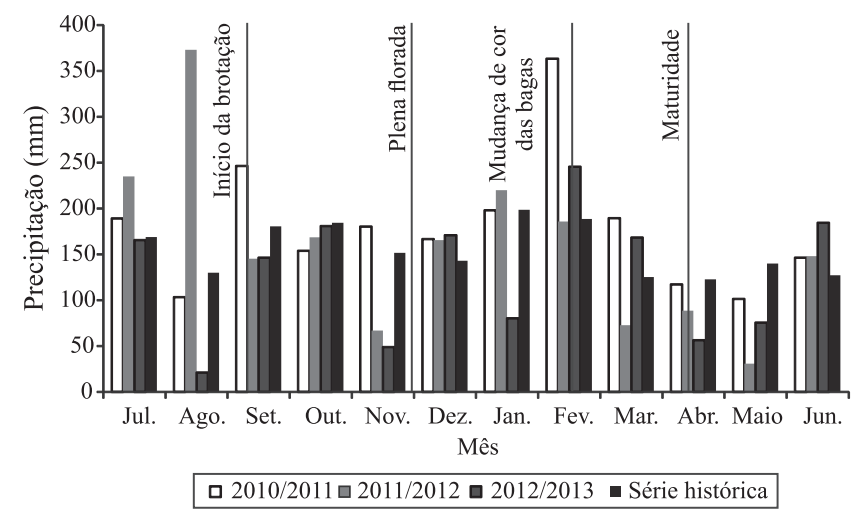

Figura 2. Acúmulo mensal da precipitação da série histórica de 1983 a 2013 e dos ciclos 2010/2011, 2011/2012 e 2012/2013, durante o ciclo vegetativo e reprodutivo da videira (Vitis vinifera), em São Joaquim, SC. colheita semelhante à de Chardonnay; as variedades Lambrusco Grasparossa, Aglianico, Negroamaro e Montepulciano apresentaram colheita tardia, como a Cabernet Sauvignon; enquanto as datas das demais foram semelhantes à da variedade Merlot.

As variedades Vermentino, Verdicchio, Rebo, Sagrantino e Sangiovese apresentaram a menor duração média do subperíodo entre a mudança de cor das bagas até a maturidade das uvas, entre 50 e 55 dias. As variedades com esse período mais curto podem adaptar-se mais facilmente a climas mais frios e a altitudes mais elevadas, visto que necessitam de menos graus-dia para completar a maturação (Fregoni, 2006). De fato, o desempenho dessas variedades destacou-se do das demais, pela qualidade das uvas e pelas produtividades obtidas (Tabelas 2 e 3).

Quando a estação de crescimento é mais curta, como em regiões de climas mais frios, as variedades de maturação precoce são as mais indicadas; enquanto que, para climas quentes, as variedades de maturação tardia são recomendadas, já que apresentam condições de completar sua maturação (Hall \& Jones, 2010).

As produtividades médias variaram de $0,86 \mathrm{~kg}$ por planta, ou 1,91 $\mathrm{Mg} \mathrm{ha}^{-1}$, para Lambrusco Grasparossa, a $3 \mathrm{~kg}$ por planta, ou $6,66 \mathrm{Mg} \mathrm{ha}^{-1}$, para Montepulciano (Tabela 2). As variedades Vermentino, Sangiovese, Negroamaro, Sagrantino e Montepulciano se destacaram com produtividades acima de $4 \mathrm{Mg} \mathrm{ha}^{-1}$.

As variáveis número de cachos, fertilidade de gemas e produtividade apresentaram elevados coeficientes de variação, principalmente no caso das variedades Prosecco e Aleatico. Esses resultados indicam elevada variabilidade da adaptação das variedades entre as safras, no que se refere, por exemplo, à regularidade da produção.

As variedades Verdicchio, Aleatico, Ancellotta, Sagrantino e Montepulciano apresentaram os maiores teores médios (acima de $21^{\circ}$ Brix) de sólidos solúveis totais (Tabela 3). Nos três ciclos avaliados, todas as variedades estudadas (exceto Prosecco e Lambrusco Grasparossa) atingiram níveis apropriados para a elaboração de vinhos de qualidade (18 a $22^{\circ}$ Brix).

Os valores de acidez titulável, nos três ciclos avaliados, foram adequados para elaboração de vinhos brancos. Porém, para as variedades destinadas à elaboração de vinhos tintos, alguns valores foram elevados (acima de $190 \mathrm{meq} \mathrm{L}^{-1}$ ), como para Aglianico, Lambrusco Grasparossa e Negroamaro 
Tabela 1. Datas médias de ocorrência dos principais estádios fenológicos de 12 variedades de uvas viníferas (Vitis vinifera) autóctones italianas, em São Joaquim, SC.

\begin{tabular}{|c|c|c|c|c|c|}
\hline Ciclo & Data da poda & Início da brotação & Plena florada & Mudança da cor das bagas $(50 \%)$ & Maturidade \\
\hline & \multicolumn{5}{|c|}{ Prosecco } \\
\hline $2010 / 2011$ & 20/ago. & 22/ago. & $15 /$ nov. & 8/fev. & 11/abr. \\
\hline $2011 / 2012$ & 15/ago. & 15/ago. & $21 /$ nov. & $22 /$ fev. & $25 /$ abr. \\
\hline $2012 / 2013$ & 10/ago. & 13/ago. & $-(1)$ & - & - \\
\hline \multirow[t]{2}{*}{ Média \pm DP } & $15 /$ ago. \pm 5 & $16 /$ ago. \pm 5 & $18 /$ nov. \pm 4 & $15 /$ fev. \pm 10 & $18 /$ abr. \pm 10 \\
\hline & \multicolumn{5}{|c|}{ Vermentino } \\
\hline $2010 / 2011$ & 31/ago. & $8 /$ set. & 6/dez. & $22 /$ fev. & 13/abr. \\
\hline $2011 / 2012$ & $14 /$ set. & $30 /$ set. & 15/dez. & $28 /$ fev. & 19/abr. \\
\hline $2012 / 2013$ & $12 /$ set. & $17 /$ set. & $27 /$ nov. & $7 /$ fev. & 9/abr. \\
\hline \multirow[t]{2}{*}{ Média \pm DP } & $8 /$ set. \pm 8 & $18 /$ set. \pm 11 & $6 /$ dez. \pm 9 & $19 /$ fev. \pm 11 & $13 /$ abr. \pm 5 \\
\hline & \multicolumn{5}{|c|}{ Verdicchio } \\
\hline $2010 / 2011$ & 26/ago. & 30/ago. & $4 /$ dez. & $16 /$ fev. & 13/abr. \\
\hline $2011 / 2012$ & 9/set. & 9/set. & $2 / \mathrm{dez}$ & $20 /$ fev. & $10 /$ abr. \\
\hline $2012 / 2013$ & 28/ago. & 9/set. & $27 /$ nov. & 9/fev. & 9/abr. \\
\hline \multirow[t]{2}{*}{ Média \pm DP } & $31 /$ ago. \pm 8 & $5 /$ set. \pm 6 & $1 /$ dez. \pm 4 & $15 /$ fev. \pm 6 & $10 /$ abr. \pm 2 \\
\hline & \multicolumn{5}{|c|}{ Aglianico } \\
\hline $2010 / 2011$ & 31/ago. & $10 /$ set. & 16/dez. & $1 /$ mar. & 4/maio \\
\hline $2011 / 2012$ & $13 /$ set. & $28 /$ set. & $14 /$ dez. & $14 /$ fev. & $8 /$ maio \\
\hline $2012 / 2013$ & 6/set. & $17 /$ set. & $30 /$ nov. & $12 /$ fev. & $22 / a b r$. \\
\hline \multirow{2}{*}{ Média \pm DP } & $6 /$ set. \pm 7 & $18 /$ set. \pm 9 & 10/dez. \pm 9 & $18 /$ fev. \pm 10 & $1 /$ maio \pm 8 \\
\hline & \multicolumn{5}{|c|}{ Ancellotta } \\
\hline $2010 / 2011$ & 31/ago. & 8/set. & 2/dez. & $13 /$ fev. & 13/abr. \\
\hline $2011 / 2012$ & $13 /$ set. & $28 /$ set. & $7 / \mathrm{dez}$ & $20 /$ fev. & 19/abr. \\
\hline $2012 / 2013$ & 6/set. & $17 /$ set. & $22 /$ nov. & $1 /$ fev. & 18/abr. \\
\hline \multirow[t]{2}{*}{ Média $\pm D P$} & $6 /$ set. \pm 7 & $17 /$ set. \pm 10 & $30 /$ nov. \pm 8 & $11 /$ fev. \pm 10 & $16 /$ abr. \pm 3 \\
\hline & \multicolumn{5}{|c|}{ Sangiovese } \\
\hline $2010 / 2011$ & 27/ago. & 6/set. & $30 /$ nov. & $21 /$ fev. & $25 /$ abr. \\
\hline $2011 / 2012$ & $5 /$ set. & $26 /$ set. & 6/dez. & $23 /$ fev. & $19 / a b r$. \\
\hline $2012 / 2013$ & 30/ago. & 9/set. & $25 /$ nov. & $10 /$ fev. & 9/abr. \\
\hline \multirow{2}{*}{ Média $\pm \mathrm{DP}$} & $31 /$ ago. \pm 5 & $13 /$ set. \pm 11 & $30 /$ nov. \pm 6 & $18 /$ fev. \pm 7 & $17 /$ abr. \pm 8 \\
\hline & \multicolumn{5}{|c|}{ Lambrusco Grasparossa } \\
\hline $2010 / 2011$ & 25/ago. & 25/ago. & $24 /$ nov. & $23 /$ fev. & $25 /$ abr. \\
\hline $2011 / 2012$ & $1 /$ set. & 9/set. & 16/dez. & $27 /$ fev. & 8/maio \\
\hline $2012 / 2013$ & 24/ago. & $3 /$ set. & - & - & - \\
\hline \multirow[t]{2}{*}{ Média \pm DP } & $27 /$ ago. \pm 4 & $2 /$ set. \pm 8 & $5 /$ dez. \pm 16 & $25 /$ fev. \pm 3 & $1 /$ maio \pm 9 \\
\hline & \multicolumn{5}{|c|}{ Negroamaro } \\
\hline $2010 / 2011$ & 30/ago. & $10 /$ set. & $12 /$ dez. & $1 /$ mar. & $4 /$ maio \\
\hline $2011 / 2012$ & $13 /$ set. & $26 /$ set. & $10 /$ dez. & $7 /$ mar. & 8/maio \\
\hline $2012 / 2013$ & 6/set. & $18 /$ set. & 3/dez. & $16 /$ fev. & $22 /$ abr. \\
\hline \multirow[t]{2}{*}{ Média \pm DP } & $6 /$ set. \pm 7 & $18 /$ set. \pm 8 & $8 /$ dez. \pm 5 & $27 /$ fev. \pm 0 & $1 /$ maio \pm 8 \\
\hline & & & Aleatico & & \\
\hline $2010 / 2011$ & 26/ago. & 25/ago. & $22 /$ nov. & $2 /$ fev. & 11/abr. \\
\hline $2011 / 2012$ & 26/ago. & $10 /$ set. & $26 /$ nov. & $8 /$ fev. & $19 /$ abr. \\
\hline $2012 / 2013$ & 20/ago. & 22/ago. & - & - & - \\
\hline Média \pm DP & $24 /$ ago. \pm 3 & $29 /$ ago. \pm 10 & $24 /$ nov. \pm 3 & $5 /$ fev. \pm 4 & $15 /$ abr. \pm 6 \\
\hline & & & Sagrantino & & \\
\hline $2010 / 2011$ & 30/ago. & $6 /$ set. & 9/dez. & $15 /$ fev. & 13/abr. \\
\hline $2011 / 2012$ & $13 /$ set. & $25 /$ set. & 8/dez. & $19 /$ fev. & 19/abr. \\
\hline $2012 / 2013$ & $12 /$ set. & $18 /$ set. & 30/nov. & $4 /$ fev. & 9/abr. \\
\hline Média $\pm \mathrm{DP}$ & $8 /$ set. \pm 8 & $16 /$ set. \pm 10 & $5 /$ dez. \pm 5 & $12 /$ fev. \pm 8 & $13 /$ abr. \pm 5 \\
\hline & & & Montepulciano & & \\
\hline $2010 / 2011$ & 28/ago. & $18 /$ set. & $17 / \mathrm{dez}$. & $3 /$ mar. & $4 /$ maio \\
\hline $2011 / 2012$ & 14 /set. & 5/out & $15 / \mathrm{dez}$ & $8 /$ mar. & $8 /$ maio \\
\hline $2012 / 2013$ & 6/set. & $22 /$ set. & 30/nov. & $15 /$ fev. & $25 /$ abr. \\
\hline Média $\pm \mathrm{DP}$ & $5 /$ set. \pm 9 & $25 /$ set. \pm 9 & $10 /$ dez. \pm 9 & $28 /$ fev. \pm 12 & $2 /$ maio \pm 7 \\
\hline & & & Rebo & & \\
\hline $2010 / 2011$ & 25/ago. & 26/ago. & $24 /$ nov. & $13 /$ fev. & 13/abr. \\
\hline $2011 / 2012$ & 26/ago. & 14 /set. & $25 /$ nov. & $16 /$ fev. & $10 / a b r$. \\
\hline $2012 / 2013$ & 20/ago. & 24/ago. & - & - & - \\
\hline Média \pm DP & $23 /$ ago. \pm 3 & $31 /$ ago. \pm 12 & $24 /$ nov. \pm 1 & $14 /$ fev. \pm 2 & $11 /$ abr. \pm 2 \\
\hline
\end{tabular}

(1)Ausência de dados em razão de ocorrência de geadas (-). 
(Tabela 3). As regiões de clima frio proporcionam, caracteristicamente, teores mais elevados de acidez nas uvas e nos vinhos, uma vez que temperaturas mais elevadas estão relacionadas à maior degradação dos ácidos (Jackson, 2008).

Os valores médios de $\mathrm{pH}$ variaram de 2,88 a 3,16 nas variedades analisadas (Tabelas 3 ). A acidez regula o $\mathrm{pH}$, que é muito importante no desempenho da fermentação malolática para o sabor, na estabilidade biológica e na coloração do vinho (Fregoni, 2006). O pH ótimo para a elaboração de vinhos tintos não deve ser superior a 3,2 (Fregoni, 2006). No entanto, as variedades Aglianico, Lambrusco Grasparossa e Negroamaro apresentaram valores médios de $\mathrm{pH}$ inferiores a 3,0, o que indica maturação deficiente da uva.
As variedades Ancellotta, Lambrusco Grasparossa, Aglianico, Montepulciano e Rebo se destacaram com elevados teores de antocianinas monoméricas totais (Tabela 3). O efeito da altitude sobre o desenvolvimento e a composição da uva já foi estudado por outros autores. Nas variedades tintas portuguesas Touriga Nacional e Touriga Francesa, foram observados aumentos nos teores de antocianinas, quando a altitude passou de 150 para $250 \mathrm{~m}$ acima do nível do mar (Mateus et al., 2001). Entretanto, além da altitude, as condições climáticas também interferem na produção de antocianinas (Downey et al., 2006).

As condições climáticas de São Joaquim favoreceram a maturação fenólica da uva, um vez que o acúmulo de antocianinas durante a maturação apresenta correlação

Tabela 2. Índices produtivos de 12 variedades de uvas viníferas (Vitis vinifera) autóctones italianas, em São Joaquim, SC.

\begin{tabular}{|c|c|c|c|c|c|c|c|c|c|c|}
\hline \multirow[t]{2}{*}{ Variedade } & \multicolumn{2}{|c|}{$\begin{array}{c}\text { Número de } \\
\text { cachos }\end{array}$} & \multicolumn{2}{|c|}{$\begin{array}{c}\text { Fertilidade } \\
\text { de gemas }\end{array}$} & \multicolumn{2}{|c|}{$\begin{array}{l}\text { Produtividade } \\
\text { (kg por planta) }\end{array}$} & \multicolumn{2}{|c|}{$\begin{array}{l}\text { Produtividade } \\
\left(\mathrm{Mg} \mathrm{ha}^{-1}\right)\end{array}$} & \multicolumn{2}{|c|}{$\begin{array}{l}\text { Peso médio } \\
\text { de cacho }(\mathrm{g})\end{array}$} \\
\hline & Média & CV $(\%)$ & Média & CV (\%) & Média & CV (\%) & Média & CV $(\%)$ & Média & CV $(\%)$ \\
\hline Prosecco & 9,60 & 75,44 & 0,65 & 66,67 & 0,92 & 84,53 & 2,05 & 84,17 & 83,17 & 24,02 \\
\hline Vermentino & 11,91 & 25,07 & 0,80 & 30,56 & 2,51 & 36,82 & 5,58 & 36,89 & 226,49 & 31,47 \\
\hline Verdicchio & 7,29 & 32,20 & 0,54 & 14,47 & 1,78 & 53,20 & 3,95 & 53,42 & 259,27 & 53,89 \\
\hline Aglianico & 17,03 & 7,87 & 0,98 & 13,67 & 1,68 & 31,84 & 3,73 & 31,69 & 94,21 & 21,52 \\
\hline Ancellotta & 17,03 & 12,74 & 1,07 & 20,96 & 1,23 & 23,13 & 2,74 & 23,10 & 72,71 & 27,97 \\
\hline Sangiovese & 12,87 & 48,35 & 0,74 & 24,72 & 2,72 & 45,77 & 6,05 & 45,74 & 210,09 & 4,29 \\
\hline Lambrusco Grasparossa & 10,66 & 47,58 & 0,68 & 52,62 & 0,86 & 52,35 & 1,91 & 52,56 & 73,84 & 6,16 \\
\hline Negroamaro & 12,17 & 15,20 & 0,90 & 8,05 & 2,05 & 31,29 & 4,56 & 31,29 & 168,74 & 24,49 \\
\hline Aleatico & 9,53 & 34,07 & 0,75 & 16,28 & 1,09 & 83,62 & 2,41 & 83,79 & 94,67 & 67,19 \\
\hline Sagrantino & 14,60 & 9,32 & 0,86 & 13,38 & 2,72 & 16,06 & 6,05 & 16,06 & 201,14 & 23,43 \\
\hline Montepulciano & 17,80 & 6,63 & 1,15 & 3,41 & 3,00 & 14,52 & 6,66 & 14,54 & 177,56 & 37,48 \\
\hline Rebo & 17,10 & 10,68 & 1,16 & 7,84 & 1,33 & 22,16 & 2,95 & 22,02 & 74,65 & 13,21 \\
\hline
\end{tabular}

Tabela 3. Índices de maturação e qualidade de 12 variedades de uvas viníferas (Vitis vinifera) autóctones italianas, em São Joaquim, SC.

\begin{tabular}{|c|c|c|c|c|c|c|c|c|c|c|}
\hline \multirow[t]{2}{*}{ Variedade } & \multicolumn{2}{|c|}{$\begin{array}{c}\text { Sólidos solúveis totais } \\
\left({ }^{\circ} \text { Brix }\right)\end{array}$} & \multicolumn{2}{|c|}{$\begin{array}{l}\text { Acidez total titulável } \\
\left(\text { meq L L }^{-1}\right)\end{array}$} & \multicolumn{2}{|c|}{$\mathrm{pH}$} & \multicolumn{2}{|c|}{$\begin{array}{c}\text { AMT } \\
\left(\mathrm{mg} \mathrm{L}^{-1}\right) \\
\end{array}$} & \multicolumn{2}{|c|}{$\begin{array}{l}\text { Polifenóis totais } \\
\left(\mathrm{mg} \mathrm{L}^{-1}\right)\end{array}$} \\
\hline & Média & CV (\%) & Média & $\mathrm{CV}(\%)$ & Média & $\mathrm{CV}(\%)$ & Média & $\mathrm{CV}(\%)$ & Média & $\mathrm{CV}(\%)$ \\
\hline Prosecco & 16,95 & 1,25 & 96,75 & 35,89 & 3,04 & 0,70 & -(1) $^{(1)}$ & - & 474,94 & 3,20 \\
\hline Vermentino & 18,12 & 4,42 & 116,33 & 5,04 & 3,18 & 3,67 & - & - & 517,32 & 3,93 \\
\hline Verdicchio & 21,20 & 4,92 & 147,90 & 1,90 & 3,07 & 4,07 & - & - & 540,04 & 7,01 \\
\hline Aglianico & 19,37 & 2,60 & 197,40 & 11,16 & 2,88 & 3,23 & $1.499,42$ & 18,99 & $1.730,67$ & 15,40 \\
\hline Ancellotta & 21,70 & 2,88 & 155,27 & 14,72 & 3,11 & 3,89 & $4.070,67$ & 3,48 & $2.515,10$ & 6,89 \\
\hline Sangiovese & 19,39 & 3,80 & 140,22 & 3,09 & 3,16 & 4,19 & 445,83 & 2,60 & 783,96 & 1,06 \\
\hline Lambrusco Grasparossa & 17,25 & 5,33 & 192,00 & 7,37 & 2,98 & 0,71 & $1.540,78$ & 9,43 & $1.541,94$ & 12,04 \\
\hline Negroamaro & 19,33 & 5,88 & 240,90 & 0,42 & 2,89 & 4,32 & 534,24 & 16,36 & 797,06 & 28,02 \\
\hline Aleatico & 20,95 & 2,36 & 135,17 & 5,05 & 3,02 & 2,58 & 631,53 & 3,22 & 735,20 & 2,99 \\
\hline Sagrantino & 21,51 & 5,99 & 179,10 & 10,79 & 3,06 & 5,89 & 852,92 & 24,08 & $1.464,43$ & 13,37 \\
\hline Montepulciano & 21,33 & 6,47 & 174,43 & 4,75 & 3,07 & 5,12 & $1.265,65$ & 14,46 & $1.385,51$ & 4,48 \\
\hline Rebo & 20,20 & 2,80 & 173,35 & 2,16 & 3,16 & 1,12 & $1.143,19$ & 11,82 & $1.298,43$ & 6,35 \\
\hline
\end{tabular}

${ }^{(1)}$ Dados não avaliados. AMT, antocianinas monoméricas totais. 
negativa com altas temperaturas e positiva com baixas temperaturas. As uvas apresentam boa coloração quando a amplitude térmica não ultrapassa $10^{\circ} \mathrm{C} \mathrm{e}$, durante a maturação, esta deve ser inferior a $15^{\circ} \mathrm{C}$ (Ubalde et al., 2010).

As variedades brancas Verdicchio e Vermentino, e as tintas Ancellotta, Aglianico, Lambrusco Grasparossa, Sagrantino e Montepulciano, destacaram-se pelos elevados teores de polifenóis totais (Tabela 3). Entre os fatores do ambiente, o clima exerce a maior influência no acúmulo de polifenóis; quanto maior a altitude, menor é a temperatura e a umidade, o que favorece o acúmulo de polifenóis totais (Mateus et al., 2001).

Pela análise dos componentes principais, foi possível observar que, na média dos três ciclos avaliados, o eixo 1 x eixo 2 explicou $70 \%$ da variabilidade total dos dados de produtividade, número de cachos por planta, sólidos solúveis totais, acidez titulável, $\mathrm{pH}$, antocianinas totais e polifenóis totais (Figura 3). Em geral, quando as variedades situam-se mais próximas do eixo da variável, maior é a correlação entre elas. Dessa forma, pôde-se notar a divisão em quatro grupos distintos, que englobaram a maioria das variedades, cada um constituído de parâmetros de similaridade.

No grupo 1, aparecem as variedades brancas Prosecco, Vermentino e Verdicchio, que apresentam, em comum, a ausência de antocianinas monoméricas totais e teores menores de polifenóis totais e de acidez total titulável. No grupo 2, estão as variedades Rebo, Sagrantino e Montepulciano, que apresentam elevados teores de sólidos solúveis totais, antocianinas monoméricas totais e polifenóis totais, além de valores intermediários de acidez total titulável. No grupo 3, está a variedade Ancellotta, com os maiores teores de antocianinas monoméricas totais e polifenóis totais. No grupo 4, estão as variedades Aglianico, Negroamaro e Lambrusco Grasparossa, com baixas produtividades e elevados teores de acidez total titulável. Sangiovese e Aleatico aparecem com características químicas semelhantes, mas com diferenças marcantes na produtividade.

De forma geral, as variedades tintas tardias, quando cultivadas em locais de clima frio, têm dificuldade em completar a maturação e mantêm elevados teores

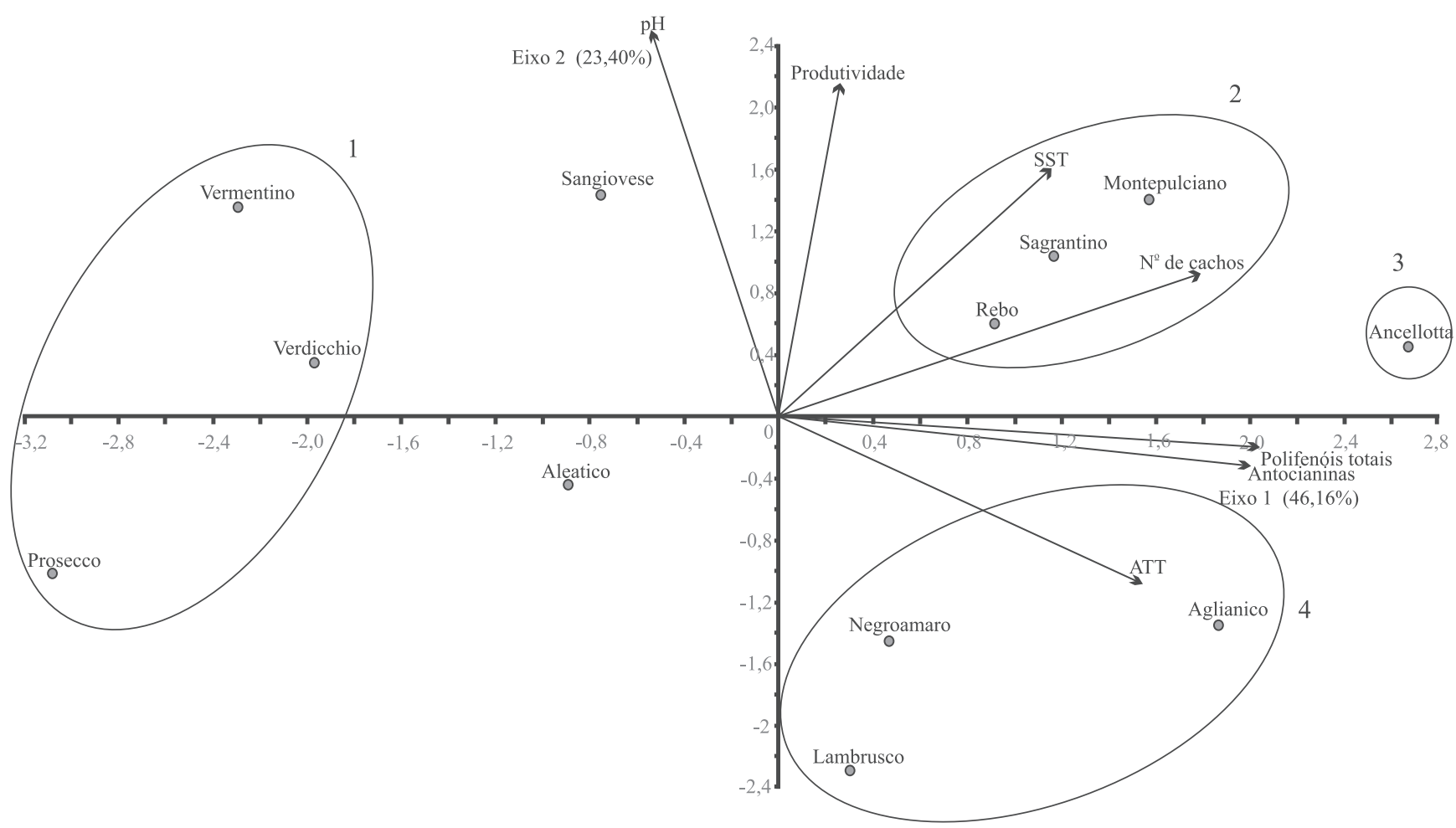

Figura 3. Análise de componentes principais realizada com produtividade $\left(\mathrm{Mg} \mathrm{ha}^{-1}\right)$, número de cachos por planta, sólidos solúveis totais (SST), acidez total titulável (ATT), pH, antocianinas totais e polifenóis totais de 12 variedades de uvas viníferas (Vitis vinifera) autóctones italianas, em São Joaquim, SC. 
de acidez no momento da colheita (Jackson, 2008). As variedades originadas do sul da Itália, como Negramaro e Aglianico, apresentaram valores de acidez entre 197 e $240 \mathrm{meq} \mathrm{L}^{-1}$. Isso pode estar relacionado ao grau de satisfação inadequado da exigência térmica para o desenvolvimento dessas variedades. Em suas respectivas regiões típicas de cultivo, ocorrem temperaturas médias históricas de aproximadamente $21,7^{\circ} \mathrm{C}$ na época de maturação (agosto, setembro e outubro) (Malinovski, 2013); em contrapartida, na média dos três ciclos avaliados em São Joaquim, a temperatura média dos meses de maturação (fevereiro, março e abril) foi de $15,7^{\circ} \mathrm{C}$.

Climas mais frios são caracterizados por temperaturas mais baixas no outono, que, em combinação com grandes variações da temperatura diurna, levam ao atraso do desenvolvimento da uva. Isso resulta em maior equilíbrio entre os níveis de açúcar, ácido e de $\mathrm{pH}$, e mais constituintes de aroma e de sabor são acumulados, o que, em geral, produz vinhos de maior qualidade (Jackson, 2008).

As variedades brancas apresentaram boa adaptação, exceto as de brotação precoce. Essas variedades necessitam de teores de acidez mais elevados do que as destinadas à elaboração de vinhos tintos, para produzirem vinhos de qualidade.

\section{Conclusões}

1. As baixas temperaturas, durante a brotação, e a precipitação pluvial, particularmente no período de maturação, são os aspectos climáticos mais limitantes para as variedades de videiras (Vitis vinifera) avaliadas à elevada altitude, em São Joaquim, Santa Catarina.

2. A amplitude térmica durante o período de maturação contribui para o acúmulo de compostos fenólicos nas uvas das variedades avaliadas.

3. As variedades mais bem adaptadas às condições de São Joaquim são as brancas Vermentino e Verdicchio, e as tintas Sangiovanese, Sagrantino e Montepulciano.

\section{Agradecimentos}

À Província Autônoma de Trento e à Associazione Trentini nel Mondo, pelo apoio financeiro e pela gestão dos recursos do projeto Tecnologias para o Desenvolvimento da Vitivinicultura Catarinense.

\section{Referências}

ANDREINI, L.; VITI, R.; SCALABRELLI, G. Study on the morphological evolution of bud break in Vitis vinifera L. Vitis, v.48, p.153-158, 2009.

BAILLOD, M.; BAGGIOLLINI, M. Les stades repères de la vigne. Revue Suisse de Viticulture, Arboriculture, Horticulture, v.25, p.7-9, 1993.

BENEZ, M.C.; CHANIN, Y.M.A.; LAUS NETO, J.A.; BRAGA, H.J.; PUNDEK, M.; MOLINARI, A.; ROSSO, R.; CARRIÃO,S.L.; BACIC, I.L.Z. Dados e informações biofísicas da Unidade de Planejamento Regional Planalto Sul Catarinense. Florianópolis: Epagri, 2002. 76p.

BRIGHENTI, A.F.; BRIGHENTI, E.; BONIN, V.; RUFATO, L. Caracterização fenológica e exigência térmica de diferentes variedades de uvas viníferas em São Joaquim, Santa Catarina Brasil. Ciência Rural, v.43, p.1162-1167, 2013. DOI: 10.1590/ S0103-84782013005000082.

BURIN, V.M.; SILVA, A.L. da; MALINOVSKI, L.I.; ROSIER, J.P.; FALCÃO, L.D.; BORDIGNON-LUIZ, M.T. Characterization and multivariate classification of grapes and wines of two Cabernet Sauvignon clones. Pesquisa Agropecuária Brasileira, v.46, p.474-481, 2011. DOI: 10.1590/S0100-204X2011000500004.

CALÒ, A.; SCIENZA, A.; COSTACURTA, A. Vitigni d'Italia. Bologna: Edagricole, 2006. 919p.

CHAVARRIA, G.; SANTOS, H.P. dos; SÔNEGO, O.R.; MARODIN, G.A.B.; BERGAMASCHI, H.; CARDOSO, L.S. Incidência de doenças e necessidade de controle em cultivo protegido de videira. Revista Brasileira de Fruticultura, v.29, p.477-482, 2007. DOI: 10.1590/S0100-29452007000300014.

DELOIRE, A.; VAUDOUR, E.; CAREY, V.; BONNARDOT, V.; VAN LEEUWEN, C. Grapevine responses to terroir: a global approach. Journal International des Sciences de la Vigne et du Vin, v.39, p.149-162, 2005.

DOWNEY, M.O.; DOKOOZLIAN, N.K.; KRSTIC, M.P. Cultural practice and environmental impacts on the flavonoid composition of grapes and wine: a review of recent research. American Journal of Enology and Viticulture, v.57, p.257-268, 2006.

FREGONI, M. Viticoltura di qualitá. Verona: Tecniche Nuove, 2006. 826p.

GIUSTI, M.M.; WROLSTAD, R.E. Characterization and measurement of anthocyanins by UV-visible spectroscopy. In: CURRENT protocols in food analytical chemistry. New York: J. Wiley and Sons, 2001. DOI: 10.1002/0471142913.faf0102s00.

GRIS, E.F.; MATTIVI, F.; FERREIRA, E.A.; VRHOVSEK, U.; PEDROSA, R.C.; BORDIGNON-LUIZ, M.T. Proanthocyanidin profile and antioxidant capacity of Brazilian Vitis vinifera red wines. Food Chemistry, v.126, p.213-220, 2011. DOI: 10.1016/j. foodchem.2010.10.102.

HALL, A.; JONES, G.V. Spatial analysis of climate in winegrape-growing regions in Australia. Australian Journal of Grape and Wine Research, v.16, p.389-404, 2010.

JACKSON, D.I.; LOMBARD, P.B. Environmental and management practices affecting grape composition and wine quality - a review. 
American Journal of Enology and Viticulture, v.44, p.409-430, 1993.

JACKSON, R.S. Wine science: principles and applications. $3^{\text {rd }}$ ed. San Diego: Elsevier, 2008. 789p.

LUCIANO, R.V.; ALBUQUERQUE, J.A.; RUFATO, L.; MIQUELlUTI, D.J.; WARMLING, M.T. Condições meteorológicas e tipo de solo na composição da uva 'Cabernet Sauvignon'. Pesquisa Agropecuária Brasileira, v.48, p.97-104, 2013. DOI: 10.1590/s0100-204X2013000100013.

MALINOVSKI, L.I. Comportamento viti-enológico da videira (Vitis vinifera $\mathbf{L}$.) de variedades autóctones italianas na região dos Campos de Palmas em Água Doce - SC - Brasil. 2013. 255p. Tese (Doutorado) - Universidade Federal de Santa Catarina, Florianópolis.

MALINOVSKI, L.I.; WELTER, L.J.; BRIGHENTI, A.F.; VIEIRA, H.J.; GUERRA, M.P.; SILVA, A.L. da. Highlands of Santa Catarina/ Brazil: a region with high potential for wine productioN. Acta Horticulturae, v.931, p.433-440, 2012.

MANDELLI, F.; BERLATO, M.A.; TONIETTO, J.; BERGAMASCHI, H. Fenologia da videira na Serra Gaúcha. Pesquisa Agropecuária Gaúcha, v.9, p.129-144, 2003.

MANNINI, F. Italian indigenous grapevine cultivars: guarantee of genetic biodiversity and economic resources. Acta Horticulturae ISHS, v.652, p.87-95, 2004.

MARGONI, M.; MATTEDI, F. Diradamento chimico su Pinot grigio per ridurre la compatezza sul grappolo. L'Informatore Agrario, v.19, p.71-74, 2004.
MATEUS, N.; MARQUES, S.; GONÇALVES, A.C.; MACHADO, J.M.; FREITAS, V. de. Proanthocyanidin composition of red Vitis vinifera varieties from the Douro valley during ripening: influence of cultivation altitude. American Journal of Enology and Viticulture, v.52, p.115-121, 2001.

RECUEIL des méthodes internationales d'analyse des vins et des moûts. Paris: Office International de la Vigne et du Vin, 2009. 368p.

SCHNEIDER, A. Aspetti genetici nello studio dei vitigni del territorio. Quaderni Di Scienze Viticole Ed Enologiche 2005-2006, v.28, p.7-16, 2006.

SHEPHERD, G.J. FITOPAC 2: manual do usuário. Campinas: Unicamp, 2010. 91p.

SINGLETON, V.L.; ROSSI, J.A. Colorimetry of total phenolics with phosphomolybdic-phosphotungstic acid reagent. American Journal of Enology and Viticulture, v.16, p.144-158, 1965.

SOLOS do Estado de Santa Catarina. Rio de Janeiro: Embrapa Solos, 2004. 726p. (Embrapa Solos. Boletim de pesquisa e desenvolvimento, 46).

TONIETTO, J.; CARBONNEAU, A. A multicriteria climatic classification system for grape-growing regions worldwide. Agricultural and Forest Meteorology, v.124, p.81-97, 2004. DOI: 10.1016/j.agrformet.2003.06.001.

UBALDE, J.M.; SORT, X.; ZAYAS, A.; POCH, R.M. Effects of soil and climatic conditions on grape ripening and wine quality of Cabernet SauvignoN. Journal of Wine Research, v.21, p.1-17, 2010. DOI: $10.1080 / 09571264.2010 .495851$.

Recebido em 13 de fevereiro de 2014 e aprovado em 28 de maio de 2014 